\title{
The efficiency of mobile hydraulic system with diesel engine and axial piston pump analysis
}

\author{
Murat Kapsiz
}

Corresponding Author: mkapsiz@gmail.com

Submitted : 17/07/2020

Revised : 26/08/2021

Accepted :06/09/2021

\begin{abstract}
Hydraulic systems are used in a wide variety of applications, stationary as well as mobile. Hydraulic pumps and motors are used in many cases for both propulsion and various work functions and are thus often a significant user of energy. Efficiency performance of mobile hydraulic systems over a wide range of pressure and speed conditions is crucially important for power unit to save energy. In this study, the efficiency of a mobile hydraulic system is studied. Mobile hydraulic systems are equipped with diesel engine as power unit and axial piston pumps used for hydraulic power. The relationships between the efficiency of the axial piston pump and the power loss and the efficiency of diesel engine and the output power were explained by graphics. The average power loss of axial piston pump has changed from $0.1 \mathrm{~kW}$ to $2.5 \mathrm{~kW}$. Losses of an axial piston pump have been determined; thus, fuel consumption and $\mathrm{CO} 2$ emission caused by these losses were shown by graph. The $\mathrm{CO} 2$ emission was affected by the increase in pressure and speed; it reached from $5.231 \mathrm{~kg} / \mathrm{h}$ to $5.61 \mathrm{~kg} / \mathrm{h}$. The research focused on analysis for axial piston pump in mobile applications, with emphasis on pump losses, fuel consumption, and $\mathrm{CO} 2$ emission.
\end{abstract}

Keywords: Efficiency; Losses; Axial piston pump; CO2 Emission; Diesel engine.

\section{NOMENCLATURE}

$\begin{array}{ll}\mathrm{n} & : \text { Shaft speed } \\ \mathrm{P}_{\mathrm{M}} & : \text { Mechanical power } \\ \mathrm{P}_{\mathrm{H}} & : \text { Hydraulic power } \\ \mathrm{P}_{(\mathrm{L}, \mathrm{tot})} & : \text { Total power loss } \\ \mathrm{P}_{(\mathrm{L}, \mathrm{hmec})} & : \text { Hydromechanical power loss } \\ \mathrm{P}_{(\mathrm{L}, \mathrm{vol})} & : \text { Volumetric power loss } \\ \mathrm{p}_{\mathrm{o}} & : \text { Output pressure } \\ \mathrm{Q}_{\mathrm{i}} & : \text { Input flow } \\ \mathrm{Q}_{\mathrm{o}} & : \text { Output flow }\end{array}$




$\begin{array}{ll}\mathrm{Q}_{\mathrm{th}} & : \text { Theoretical flow } \\ \mathrm{T}_{\mathrm{th}} & : \text { Theoretical torque } \\ \mathrm{T}_{\mathrm{me}} & : \text { Measurement torque } \\ \mathrm{T}_{\mathrm{L}} & : \text { Torque loss } \\ \mathrm{V}_{\mathrm{d}} & : \text { Volumetric displacement } \\ \omega & : \text { Angular velocity } \\ \Delta \mathrm{p} & : \text { Differential pressure } \\ \eta_{\text {pump }} & : \text { Pump efficiency } \\ \eta_{\text {hmec }} & : \text { Hydro-mechanical efficiency } \\ \eta_{\mathrm{vol}} & : \text { Volumetric efficiency. }\end{array}$

\section{INTRODUCTION}

Hydraulic systems are composed by typically high force, low speed actuators. Many mobile hydraulic applications require control with high force and low speed of mechanical parts, where weight is a concern, and other applications are composed of high-density materials compared to low density fluids that are the primary reason force behind fluid power. For this reason, the power weight ratio (PWR) of hydraulics is typically more than other applications (Manring, 2005). Increasing the energy efficiency of mobile hydraulic systems has been improved in recent years. Productivity is improved with the design of new components and better analysis of system requirements. Nowadays, the control of the components in the mobile hydraulic system is usually done with digital control systems. This control with electrical signals increases the speed and performance of the mobile hydraulic system (Williamson \& Ivantsysnova, 2010; Rydberg, 2015). Hydraulic pumps are used in many systems as hydraulic power unit of excavators, presses, cranes, and loaders (Ge et al., 2017; Zhang et al., 2017). In addition, it is highly preferred in mobile construction machines due to its power and size ratio. Hydraulic systems have some advantages such as low wear, high service life, overload protection, and possibility to accumulate energy. Hydraulic systems must provide many requirements such as acquisition costs, dependability, service life, energy consumption, equipment dimensions, weight, emission reduction, and safety (Vašina et al., 2018).

Energy consumption and emission reducing in mobile hydraulic machines are related to the hydraulic unit and the diesel engine that provides power to this unit. There is a trend for reducing energy consumption of hydraulic system by minimizing energy losses (Yu \& Ahn, 2019; Sgro et al., 2010). The optimal energy consumption requires that all losses, flow, pressure, and mechanical losses be minimized (Rydberg, 2015; Xu et al., 2016). The loss of energy in the hydraulic system occurs in hydraulic pumps, valves, hoses, and actuators. Although the energy loss values vary according to the type of pump and valve preferred, the average efficiency of the mobile hydraulic system is around $21 \%$ (Love et al., 2012).

Mobile hydraulic systems convert rotary mechanical power from internal combustion engines to fluid power by turning the input shaft of a hydraulic pump. Hydraulic control valves direct the pump flow to machine actuators that use cylinders to convert fluid power back to mechanical power. The energy transmission and conversion are schematically shown in Fig. 1. The energy conversion changes in chemical, mechanical, hydraulic, and mechanical 
cases. The losses are constantly decreasing from the internal combustion engine to the actuator. In connection with this, the system efficiency decreases continuously. Although the amount of emissions varies greatly depending on the internal combustion engine, it is also closely related to the efficiency of the hydraulic system and leaks to the external environment. Because efficiency changes the hydraulic system directly, we change the working performance of the desired combustion engine. The energy consumption of the whole system increases continuously towards the actuator, and the energy entering the system decreases continuously.

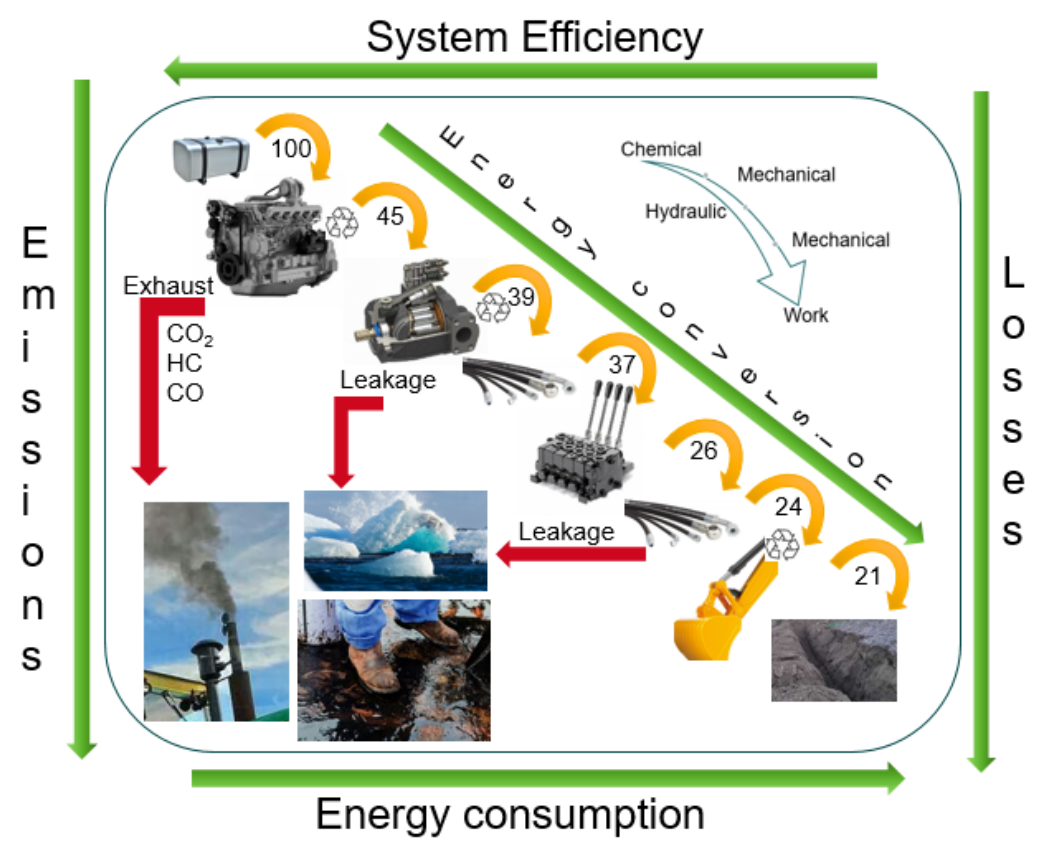

Figure 1. Losses, emissions, energy conversion, energy transmission, and efficiency at mobile hydraulic system.

In order to analyze the system efficiency better, the change of the energy entering the system within the system is expressed with numbers. Here, considering the efficiency values of a standard mobile hydraulic system in the literature, the variation of the energy passing through the system elements has been evaluated. The amount of energy starting with the combustion engine has continuously decreased by $21 \%$ in the latest actuator.

Fuel efficiency and low emissions of such mobile hydraulic application are important factors for manufacturers and designers to be competitive on market. The key challenge for improving the performance and fuel economy of internal combustion engines is the reduction of power losses (Ponomarev et al., 2014, Ali et al., 2016). The total power generated by an internal combustion engine is decreased approximately between $60 \%$ and $74 \%$ because of exhaust, cooling, and friction (Bhushan, 2001). This loss rate has decreased to 55\% with the developing diesel technologies. In Fig. 2, efficiency analysis is performed according to the highest performance diesel engines. 

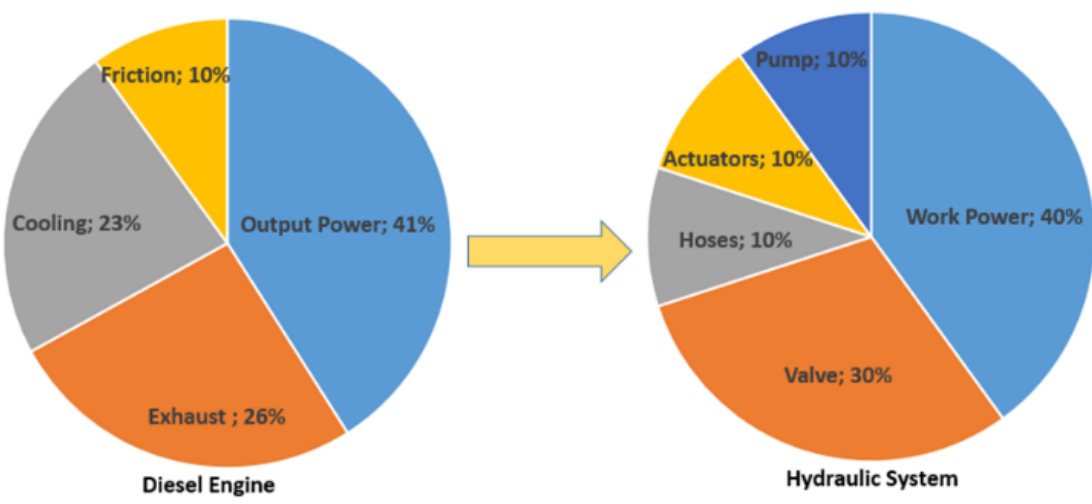

Figure 2. Losses ratios of diesel engine and hydraulic system.

Hydraulic pumps have two loss sources as hydromechanical and volumetric losses. Moving parts of hydraulic pump must seal at tribological interfaces to minimize leakage through gaps. Thus, an improvement in volumetric efficiency can be achieved. Therefore, efficient and smart design mobile hydraulic systems are now in very high demand worldwide (Yang \& Pan, 2015).

In this study, the efficiency and losses of axial piston hydraulic pump are calculated based on the pressure change. Then, the performance and emission curves of the combustion engine were drawn for different running conditions. The power and torque values of the combustion engine and hydraulic pump are compared. Thus, optimum conditions were determined by establishing a relationship between system efficiency and emissions.

\section{ANALYSIS}

The specifications of the axial piston pump used in the analysis are given in Table 2. This axial piston pump is ideal for mobile applications that require little hydraulic power. The analysis is based on catalog values. Pressure ranges, different from the analysis values, were determined. Volumetric and hydromechanical efficiency values were found with the help of theoretical formulas. Power and torque loss values were determined with the help of the values in the pump characteristic curves.

Table 1. Axial Piston Pump Specifications.

\begin{tabular}{|c|c|}
\hline Specifications & Values \\
\hline Displacement max. (cm3/rev) & 32 \\
\hline Pressure max. (bar) & 300 \\
\hline Speed max. (rpm) & 2000 \\
\hline
\end{tabular}

The characteristics of the diesel engine used in the analysis are given in Table 2. This engine is especially ideal as power unit for mobile applications that require little power. The analysis is based on catalog values. Load ranges different from the analysis values were determined. Power and torque values were found with the help of theoretical formulas. Emission values were determined with the help of the values in the motor characteristic curves. 
Table 2. Diesel Engine Specifications.

\begin{tabular}{|c|c|}
\hline Specifications & Values \\
\hline Displacement (L) & 3.0 \\
\hline Cylinders & 4 \\
\hline Aspiration & Turbocharged \\
\hline Fuel & Diesel \\
\hline Dry Weight $(\mathrm{kg})$ & 322 \\
\hline Power (2000 rpm) & \\
\hline$(\mathrm{HP})$ & 70 \\
\hline$(\mathrm{kW})$ & 52 \\
\hline
\end{tabular}

The relationship between diesel engine and axial piston pump in a mobile hydraulic system is given schematically in Fig. 3.

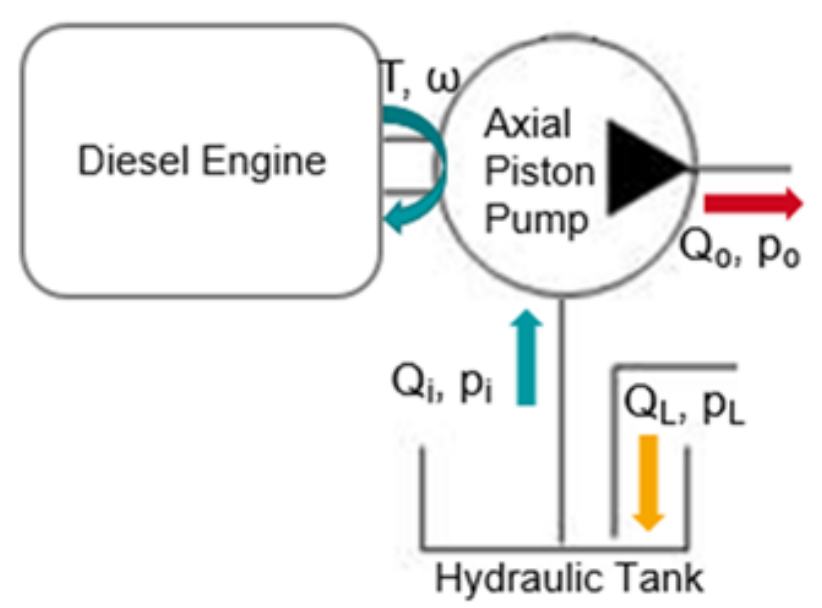

Figure 3. Schematic view of mobile hydraulic system.

The torque and rotational motion generated by the diesel engine used in the axial piston pump drive is transmitted to the pump. Mechanical power, $\mathrm{P}_{\mathrm{m}}$;

$\mathrm{P}_{\mathrm{M}}=\mathrm{T}_{\text {th }} \omega$

Hydraulic power generated by the pump, $\mathrm{P}_{\mathrm{h}}$;

$\mathrm{P}_{\mathrm{H}}=\mathrm{Q}_{\mathrm{o}} \mathrm{p}_{\mathrm{o}}$

The internal and external leakage reduce the volumetric efficiency, $\eta_{\mathrm{vol}}$; 
$\eta_{\mathrm{vol}}=\mathrm{Q}_{\mathrm{o}} / \mathrm{Q}_{\mathrm{i}}$

Hydromechanical losses occur because of tribological interfaces and hydrodynamic effect in axial piston pump. These losses cause torque loss in the axial piston pump, and it is called mechanical efficiency, $\eta_{\text {hmec }}$;

$\eta_{\mathrm{hmec}}=(\mathrm{Vd} \Delta \mathrm{p}) / 2 \pi \mathrm{T}_{\mathrm{th}}$

The overall efficiency is defined as the ratio of actual hydraulic power output to the mechanical power supplied. The overall efficiency is the product of volumetric and hydromechanical efficiencies, $\eta_{\text {pump; }}$;

$\eta_{\text {pump }}=\eta_{\mathrm{hmec}} \eta_{\mathrm{vol}}$

The total power loss of the axial piston pump occurs as hydromechanical and volumetric losses. In general, at any thermodynamic system, the sum of all separate losses needs to be equal to the total loss [Achten et al., 2019]:

$\mathrm{P}_{\mathrm{L}, \mathrm{tot}}(\Delta \mathrm{p}, \mathrm{n})=\Sigma \mathrm{i} \mathrm{P}_{\mathrm{L}, \mathrm{i}}(\Delta \mathrm{p}, \mathrm{n})$

For axial piston pump, equation (6) thus becomes

$\mathrm{P}_{\mathrm{L}, \mathrm{tot}}=\mathrm{P}_{\mathrm{L}, \mathrm{hmec}}+\mathrm{P}_{\mathrm{L}, \mathrm{vol}}$

The total loss of axial piston pump is defined as follows:

$\mathrm{P}_{\mathrm{L}, \text { tot }}=\mathrm{P}_{\mathrm{M}}-\mathrm{P}_{\mathrm{H}}=\mathrm{T}_{\text {th }} \omega-\mathrm{P}_{\mathrm{H}}$

The hydromechanical losses can be defined as

$\mathrm{P}_{\mathrm{L}, \mathrm{hmec}}=\mathrm{T}_{\mathrm{L}} \omega=\left(\mathrm{T}_{\mathrm{me}}-\mathrm{T}_{\mathrm{th}}\right) \omega$

Combining Equations (8) and (9) with Equation (7), the volumetric losses are defined as

$\mathrm{P}_{\mathrm{L}, \mathrm{vol}}=\mathrm{T}_{\mathrm{th}} \omega-\mathrm{P}_{\mathrm{H}}$

\section{RESULTS}

\section{Efficiency of Pump}

In Fig. 4, the efficiency curves of the axial piston pump are given for different pressure values. The overall efficiency of the pump, which is lower in low-pressure values, increases with increasing pressure values. The characteristic of the total yield curve is closely related to the characteristic of the hydromechanical yield curve. The reason for this is that it is the hydromechanical efficiency that affects the total efficiency change the most. While the hydromechanical efficiency at the lowest pressure value is $81 \%$, it reaches the $94 \%$ value by increasing $14 \%$ with the increase of the pressure. Since the volumetric efficiency has high values, its variability occurred in a lesser range. The volumetric efficiency, which is $99 \%$ at low pressure values, decreases $5 \%$ with the increase of pressure and decreases to $95 \%$. While the total efficiency value formed by hydromechanical and volumetric efficiency together is $80 \%$ at low pressures, it increases to $91 \%$ by increasing $13 \%$ with increasing pressure. 


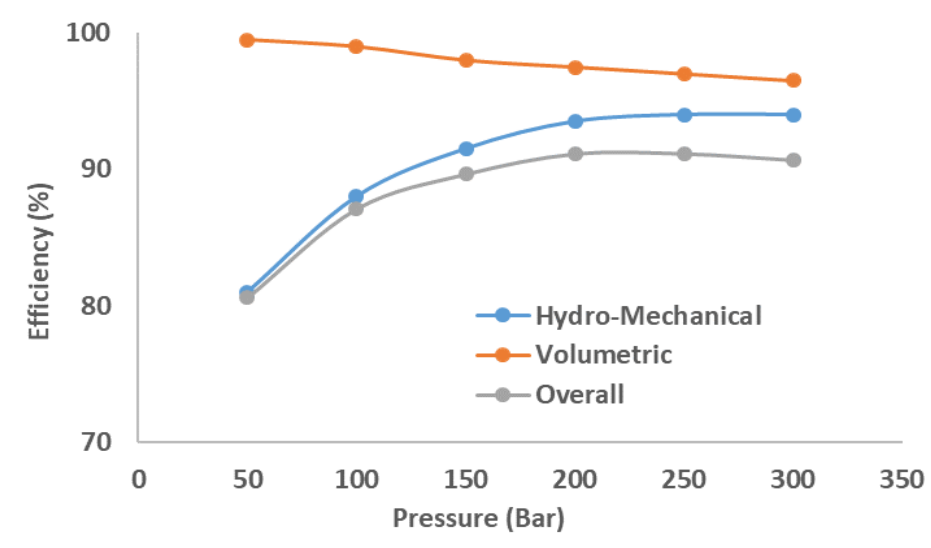

Figure 4. Pump efficiencies.

The reasons affecting the efficiency of the axial piston pump are losses. These losses vary depending on the pump operating pressure. The analysis of losses is necessary to improve pump efficiency.

Thus, the losses sources can be identified clearly, and the necessary improvements can be made. The power loss curves due to the pressure of the axial piston pump analyzed are given in Fig. 5 for different operating cycles. Since the hydraulic power produced by the pump is limited at low speeds, the power loss values are less than the high speeds. The average power loss, which is $0.1 \mathrm{~kW}$ at $300 \mathrm{rpm}$, is $0.4 \mathrm{~kW}$ at $600 \mathrm{rpm}, 0.9 \mathrm{~kW}$ at $900 \mathrm{rpm}, 1.6 \mathrm{~kW}$ at $1200 \mathrm{rpm}$, and $2.5 \mathrm{~kW}$ at $1500 \mathrm{rpm}$.

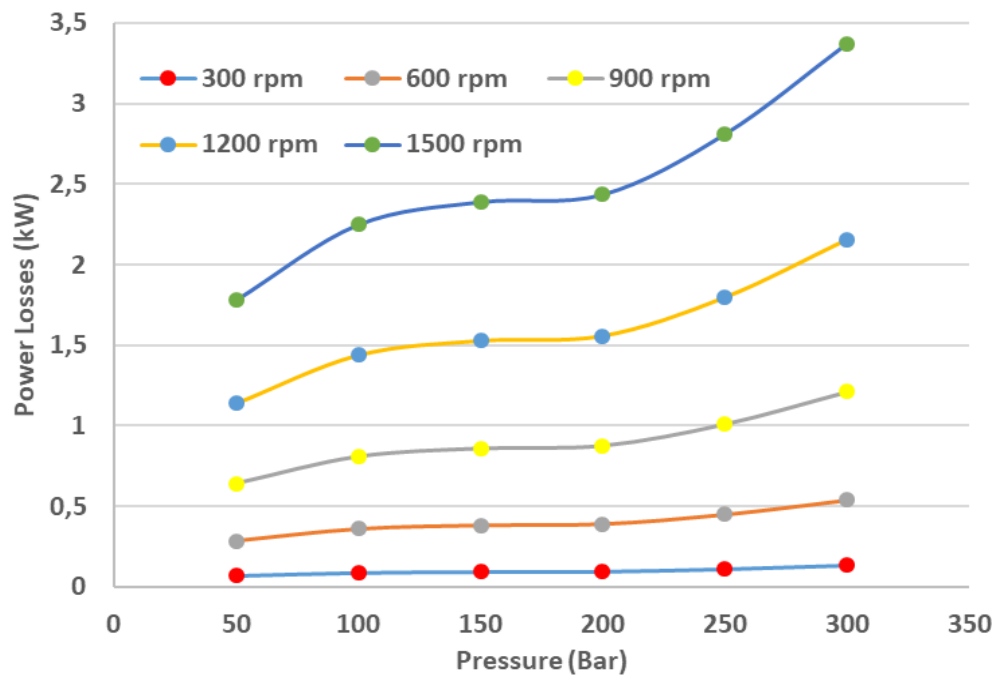

Figure 5. Power losses in pump.

When the power loss values given in Fig. 5 are evaluated with the total hydraulic power produced by the pump, the power loss rate occurs. The change of this value is given in Fig. 6 depending on the operating pressure and speed of the pump. This ratio, which takes low values at low speeds and pressures, increases with increasing speed and 
pressure. The average power loss rate is 2.55 at $300 \mathrm{rpm}, 5.10$ at $600 \mathrm{rpm}$, and 7.65 at $900 \mathrm{rpm}$. It is 10.21 at 1200 rpm and 12.76 at $1500 \mathrm{rpm}$.

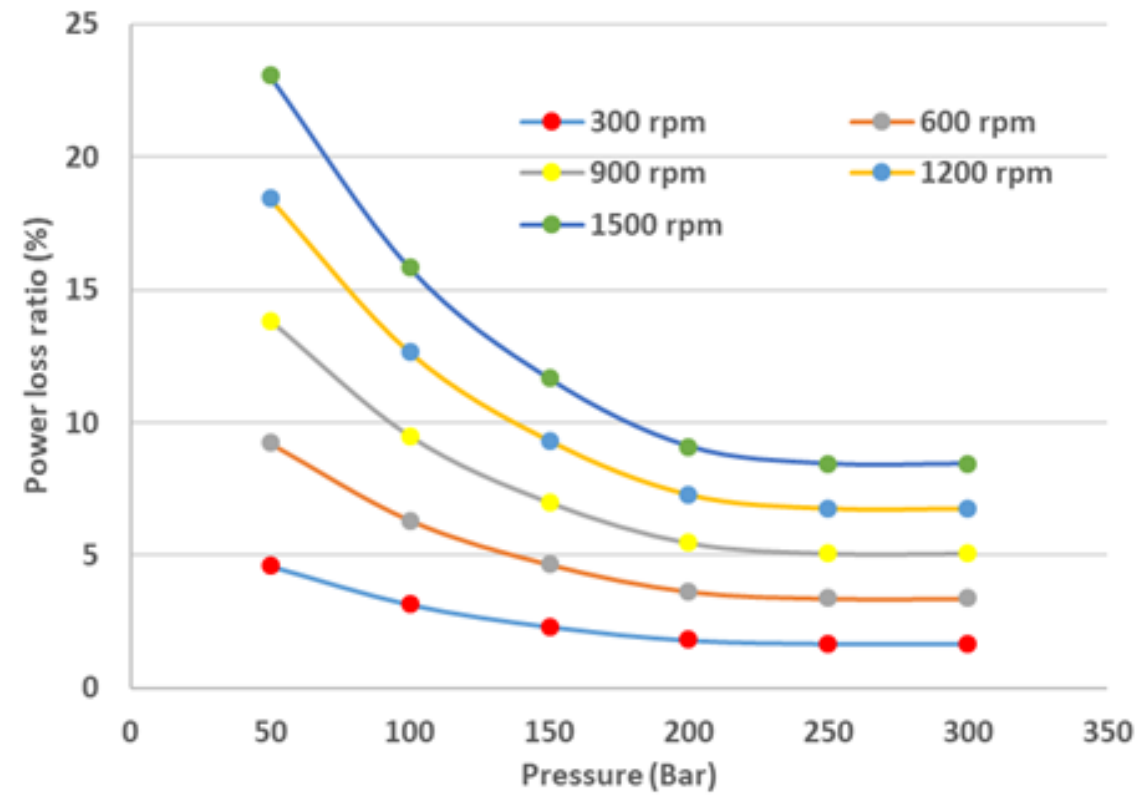

Figure 6. Power losses ratio in pump.

\section{Efficiency of Diesel Engine}

Efficiency can be expressed in various ways for internal combustion engines. Volumetric and mechanical efficiency are the most commonly used efficiency expressions. However, neither of them can meet the efficiency level for the engines with internal combustion. Therefore, effective efficiency covering all of these efficiency expressions was used in the study. In addition, the power curve with effective efficiency is important for defining the characteristics of the diesel engine. In Fig. 7, the change in both power and effective efficiency values depending on engine speed is given in the same graph.

The rise in power curve continues with the increase in engine speed. Accordingly, the effective efficiency of the engine reaches its maximum torque value of $1400 \mathrm{rpm}$. When both curves are evaluated together, despite the increase in engine power, a significant decrease in volumetric and mechanical efficiency occurs with the increasing speed. As a result, the engine tends to decrease in effective efficiency.

Therefore, when the power, torque, and specific fuel consumption of the combustion engines are evaluated together, it is seen that the effective operating speed of the engine is the speed intervals in which the engine produces the maximum torque. 


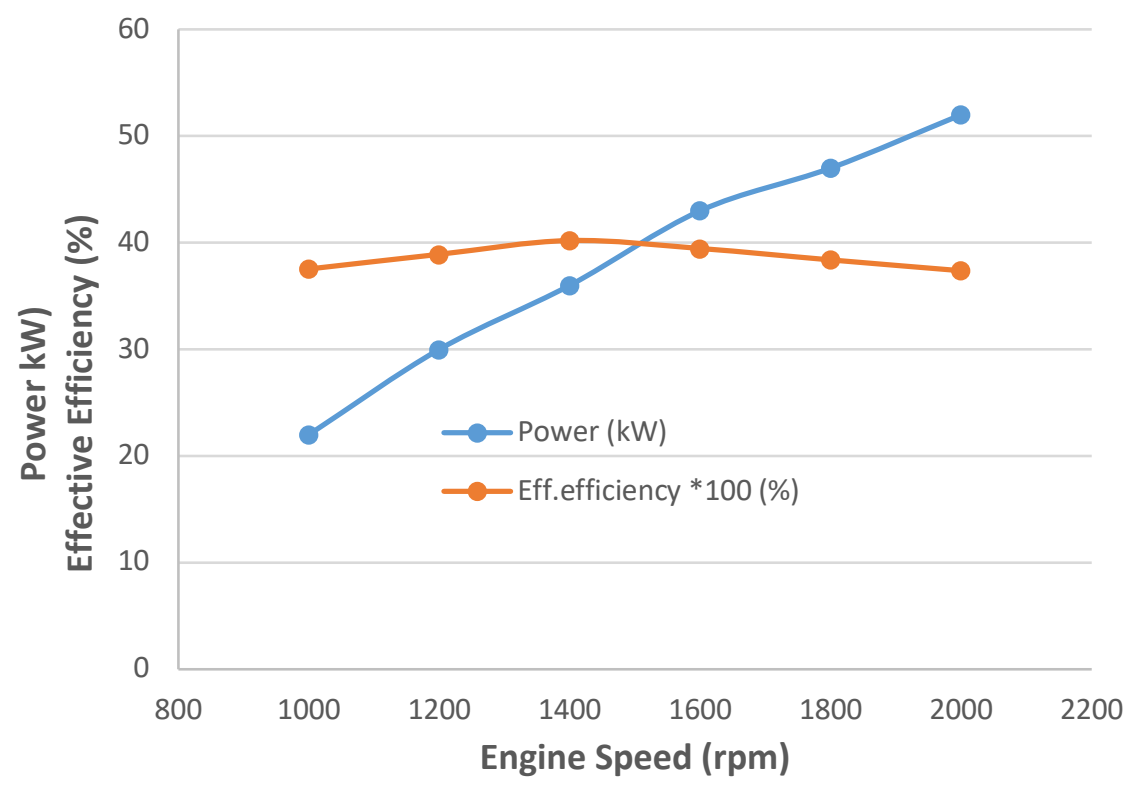

Figure 7. Power and effective efficiency of diesel engine.

The most critical aspect of diesel engines in recent years is high $\mathrm{CO} 2$ emission values. Therefore, in this study, the amount of $\mathrm{CO} 2$ emitted by the diesel engine depending on the fuel consumption was determined for a one-hour working period. The amount of mass $\mathrm{CO} 2$ emitted by the diesel engine varies approximately 3 times as much as the fuel it consumes. This change is given in Fig. 8 depending on engine speed. With the increase in engine speed, the amount of fuel consumed and $\mathrm{CO} 2$ emitted increase significantly. The relationship between these two variables is $15.76 \mathrm{~kg} \mathrm{CO} 2$ emission versus $4.9 \mathrm{~kg}$ fuel at $1000 \mathrm{rpm}$ and $37.43 \mathrm{~kg} \mathrm{CO} 2$ emission versus $11.84 \mathrm{~kg}$ fuel at $2000 \mathrm{rpm}$.

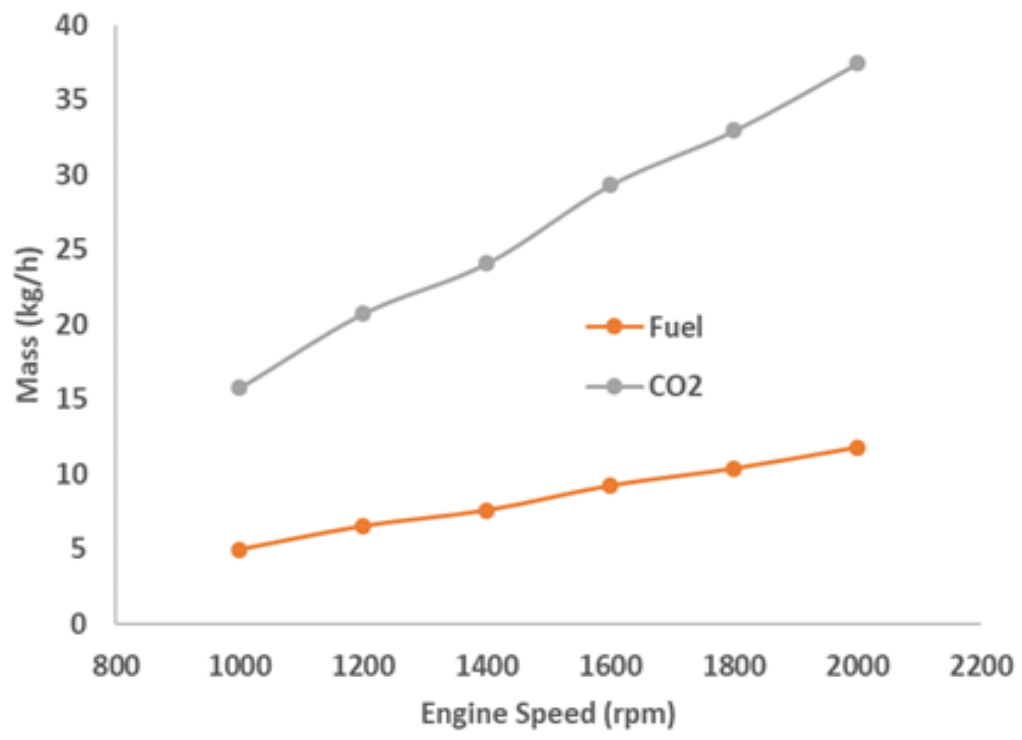

Figure 8. Fuel consumption and $\mathrm{CO} 2$ mass for $1 \mathrm{~h}$ running period. 


\section{Power Ratios}

Both diesel engine and axial piston pump efficiencies were investigated for mobile hydraulic system analysis. The relations between these two units are important for energy transformations and system efficiency. Therefore, the power transmitted from the diesel engine to the hydraulic pump was evaluated with pump losses. The power loss of the axial piston pump and the power values from the engine were proportioned in Fig. 9. This rate grows as the pressure and pump speed increase. This proportional value is 50 bar pressure and 0.3 at $300 \mathrm{rpm}$; it is 7.84 at 300 bar and $1500 \mathrm{rpm}$.

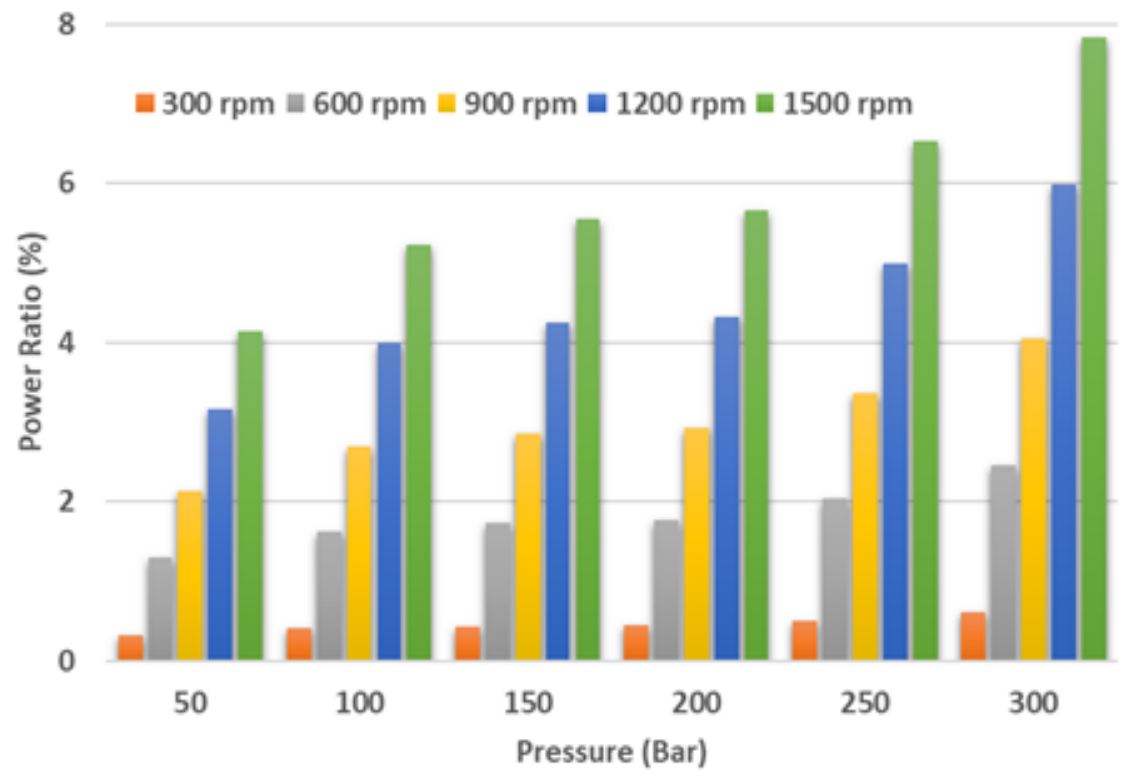

Figure 9. Ratio of Power (Power Losses of Pump/Engine Power).

Depending on the operating conditions, the hydromechanical and volumetric losses occurring in the axial piston pump consume approximately $8 \%$ of the power transmitted from the engine. This results in more fuel and $\mathrm{CO} 2$ emissions caused by lost power. The relationship between the internal combustion engine and the axial piston engine caused by the proportion made is seen more clearly.

\section{Pump Losses Effect}

In this section, the effects of the pump losses on the fuel consumed by the diesel engine, the power unit of the mobile hydraulic system, and the emission of carbon dioxide emitted during the one-hour operation period are explained with graphics.

In Figure 10, fuel consumption caused by pump losses are given in different pressure and speed ranges. With the increase in pressure and speed, the losses in the pump increase and cause excessive fuel consumption. While this value is $0.07 \mathrm{~kg} / \mathrm{h}$ in low pressure and speeds, it increases to $1.77 \mathrm{~kg} / \mathrm{h}$ in increasing pressure and speed. This shows that every improvement of hydraulic pump efficiency will positively affect the efficiency of the mobile hydraulic system. 


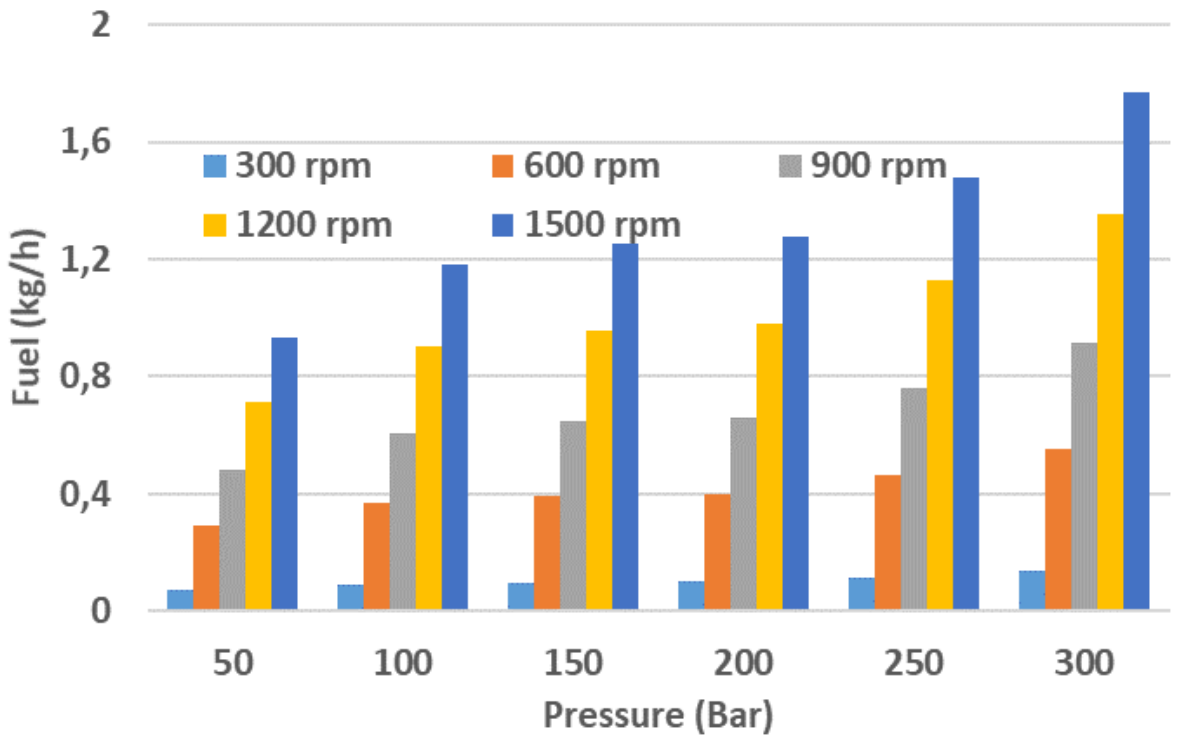

Figure 10. Effect of pump losses on fuel consumption.

$\mathrm{CO} 2$ emission caused by axial piston pump losses was given in Figure 11. Depending on the fuel consumption, the $\mathrm{CO} 2$ emission caused by the increase in pressure and speed increases. $\mathrm{CO} 2$ emission value reaches from 5.231 $\mathrm{kg} / \mathrm{h}$ to $5.61 \mathrm{~kg} / \mathrm{h}$. It is easy to see how important the improvement of pump losses is not only in the efficiency of the hydraulic system, but also in the environment.

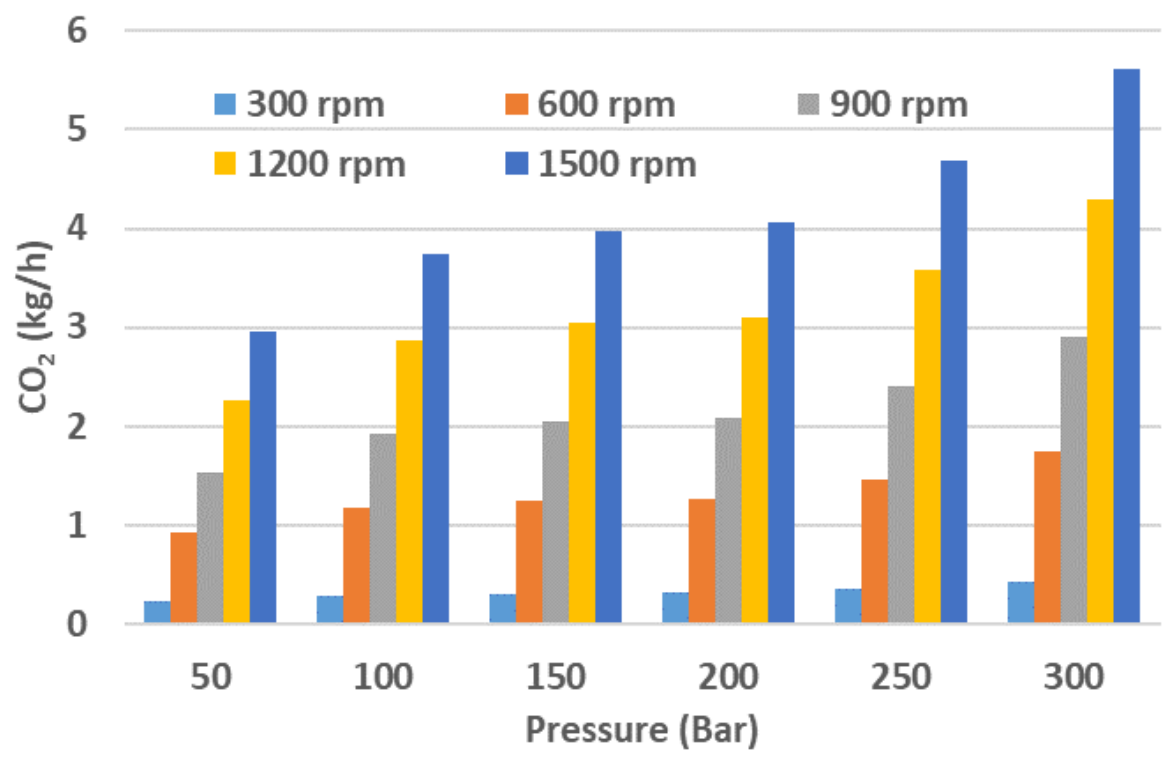

Figure 11. Effect of pump losses on $\mathrm{CO} 2$ emission. 


\section{CONCLUSION}

- Hydromechanical efficiency of axial piston pump at the lowest pressure value is $81 \%$, and it reached the $94 \%$ value by increasing $14 \%$ with the increase of the pressure.

- Volumetric efficiency of axial piston pump, which is $99 \%$ at low-pressure values, decreased $5 \%$ with the increase of pressure and decreases to $95 \%$.

- The total efficiency of axial piston pump value is $80 \%$ at low pressures; it increased to $91 \%$ by increased $13 \%$ with rising pressure.

- Since the hydraulic power produced by the pump is limited at low speeds, the power loss values are less than the high speeds. The average power loss of axial piston pump has changed from $0.1 \mathrm{~kW}$ to $2.5 \mathrm{~kW}$.

- The power loss ratio of axial piston pump takes low values at low speeds and pressures and increases with increasing speed and pressure. Average power loss ratio has risen from $2.55 \%$ to $12.76 \%$.

- With the rising in engine power, a significant decrease in volumetric and mechanical efficiency occurs with the increasing speed. As a result, the engine tends to decrease in effective efficiency.

- The amount of fuel consumed and $\mathrm{CO} 2$ emitted increased significantly with the increase in engine speed.

- The power loss of the axial piston pump and the power values from the engine were proportioned. The resulting ratio grew up as the pressure and pump speed increase. These ratio values have changed from 0.3 to 7.84 .

- Fuel consumption caused by pump losses was $0.07 \mathrm{~kg} / \mathrm{h}$ in low pressure and speeds; it increased to $1.77 \mathrm{~kg} /$ $\mathrm{h}$ in increasing pressure and speed.

- $\mathrm{CO} 2$ emissions caused by axial piston pump losses were depending on the fuel consumption. The $\mathrm{CO} 2$ emission was affected by the increase in pressure and speed, and it reached from $5.231 \mathrm{~kg} / \mathrm{h}$ to $5.61 \mathrm{~kg} / \mathrm{h}$. The improvement of pump losses is critically important not only in the efficiency of the hydraulic system, but also environmentally.

\section{REFERENCES}

Achten, P., Mommers, R., Nishiumi, T., Murrenhoff, H., Sepehri, N., Stelson, K., Palmberg, J.O. \& Schmitz, K. 2019. Proceedings of the ASME/BATH, FPMC2019, October 7-9, Sarasota, FL, USA.

Ali, M. K. A. Xianjun, H., Mai, L. Bicheng, C., Turkson, R. F. \& Qingping, C. 2016. Reducing frictional power losses and im-proving the scuffing resistance in automotive engines using hybrid nanomaterials as nano-lubricant additives, Wear 364-365 (2016) 270-281

Bhushan, B.2001. Modern Tribology Handbook, CRC Press LLC.

Ge, L., Quan, L., Zhang, X. Zhao, B. \& Yang, J. 2017. Efficiency improvement and evaluation of electric hydraulic excavator with speed and displacement variable pump, Energy Conversion and Management, (2017) 150, 62-71.

Love, L.J., Lanke, E. \& Alles, P. 2012. Estimating the Impact (Energy, Emissions and Economics) of the U.S. Fluid Power Industry, United States: N. p., Web. Doi:10.2172/1061537

Manring, N. 2005. Hydraulic Control Systems, John Wiley and Sons, Inc.

Ponomarev, P., Åman, R., Handroos, H., Immonen, P., Pyrhönen, J. \& Laurila, L.2014. High power density integrated electro-hydraulic energy converter for heavy hybrid off-highway working vehicles, Institution of Engineering and Technology (IET) (2014) Volume: 4, Issue: 4, 12, Page(s): $114-121$.

Rydberg, K. E. 2015. Energy Efficient Hydraulics -System solutions for loss minimization, National Conference on Fluid Power, Linköping University, 6 - 17 March, Linköping, Sweden. 
Sgro, S., Inderelst, M. \& Murrenhoff, H. 2010. Energy Efficient Mobile Working Machines, 7th International Fluid Power Conference Aachen. RWTH Aachen University, Germany.

Vašina, M., Hružík L. \& Bureček, A. 2018. Energy and Dynamic Properties of Hydraulic Systems, Technical Gazette 25, Suppl. 2, 382-390.

Williamson, C. \& Ivantysynova, M. 2010. Power Optimization for Multi-Actuator Pump-Controlled Systems, 7th International Fluid Power Conference Aachen, RWTH Aachen University, Germany.

Xu, B., Hu, M., Zhang, J. \& Su, Q. 2016. Characteristics of volumetric losses and efficiency of axial piston pump with respect to displacement conditions, J Zhejiang Univ-Sci A (Appl Phys \& Eng) (2016) 17(3):186201.

Yang, H., \& Pan, M. 2015. Engineering research in fluid power: a review, J Zhejiang Univ-Sci A (Appl Phys \& Eng) (2015) 16(6):427-442

Yu, Y.X.\& Ahn K.K. 2019. Energy Saving and control of a Hybrid Hydraulic Excavator Swing System, 2019 IEEE 8th International Conference on Fluid Power and Mechatronics, 10-13 April, Wuhan, China

Zhang, S., Minav, T. \& Pietola, M. 2017. Decentralized Hydraulics for Micro Excavator, the 15th Scandinavian International Conference on Fluid Power, SICFP'17, June 7-9, 2017, Linköping, Sweden 